\title{
A CONDIÇÃO EFÊMERA NA CIDADE CONTEMPORÂNEA: TRÊS PAVILHÕES TEMPORÁRIOS NO RIO DE JANEIRO (2012-2018)
}

La condición efímera en la ciudad contemporánea:

tres pabellones temporales en Río de Janeiro (2012-2018)

The ephemeral condition in the contemporary city:

three temporary pavilions in Rio de Janeiro (2012-2018)

\section{Adriana Sansão Fontes}

Professora Associada da Faculdade de Arquitetura e Urbanismo (UFRJ) e do Programa de Pós-Graduação em Urbanismo (PROURB-FAU/UFRJ). Universidad Federal de Río de Janeiro. Río de Janeiro. Brasil

adrianasansao@gmail.com

http://orcid.org/0000-0003-0648-3894

\section{Fernando Espósito Galarce}

Professor Assistente do Departamento de Arquitectura e Urbanismo (PUC-Rio)- Investigador y coordinador del Laboratorio de Observación del Espacio Habitado (LObEHab), de PPGA, PUC-Rio. Pontifícia Universidade Católica do Rio de Janeiro. Río de Janeiro. Brasil

fernando.esposito@puc-rio.br

https://orcid.org/0000-0001-9441-6012
Proyecto:

Jovem Cientista do Nosso Estado (FAPERJ) e Bolsa de Produtividade em Pesquisa PUC-Rio.

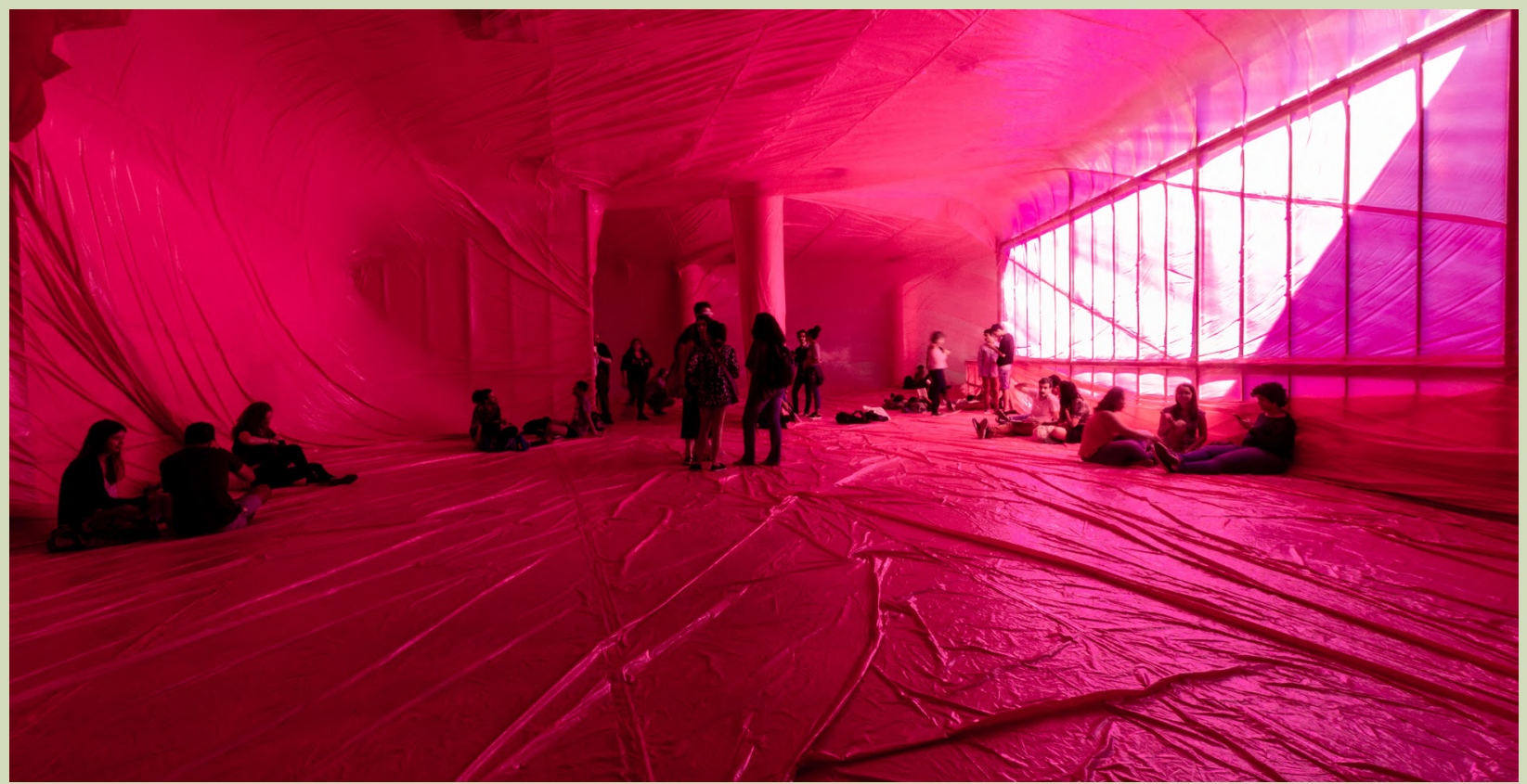




\title{
RESUMO
}

Nessas primeiras décadas do século XXI vivemos um momento específico de alta modernidade, caracterizado pela transitoriedade em várias esferas das relações sociais e econômicas, uma condição efêmera que se expressa na cidade e constrói novas dinâmicas espaciais e arquitetônicas. Esse artigo busca refletir sobre a relação entre essa condição efêmera espaço-temporal e a sociedade contemporânea, observando como ela se concretiza na cidade. Especificamente, buscamos compreender como essas características são assimiladas na arquitetura no caso dos pavilhões, uma das tipologias mais efêmeras no campo da arquitetura. Para tal, partimos da discussão de alguns autores que tratam da mudança de paradigma da modernidade para a pós modernidade, para, em seguida, sistematizar e discutir os conceitos de dinamismo, reversibilidade, flexibilidade e imprevisibilidade, com os quais serão avaliados os casos dos pavilhões temporários. Finalmente, concluímos que estes conceitos oferecem uma matriz com a qual é possível reler a vida urbana, para operar sobre novas formas de projetar e conceber o espaço de convívio e troca na cidade, respondendo, assim, à efemeridade do emotivo, histórico, físico e social.

Palavras chave: Arquitetura efêmera, arquitetura contemporânea, pavilhões, cidades, Rio de Janeiro

\section{RESUMEN}

En estas primeras décadas del siglo XXI vivimos un momento específico de alta modernidad, caracterizado por la fugacidad en diversas esferas de las relaciones sociales y económicas, una condición efímera que se expresa en la ciudad y construye nuevas dinámicas espaciales y arquitectónicas. Este artículo busca reflexionar sobre la relación entre esta condición efímera y la sociedad contemporánea, observando cómo se materializa en la ciudad. Específicamente, buscamos entender cómo se asimilan estas características en la arquitectura en el caso de los pabellones, una de sus tipologías más efímeras. Con este fin, partimos de la discusión de algunos autores que se ocupan del cambio de paradigma de la modernidad a la posmodernidad, para luego sistematizar y discutir los conceptos de dinamismo, reversibilidad, flexibilidad e imprevisibilidad, con los que se evaluarán los casos de los pabellones temporarios. Finalmente, concluimos que estos conceptos ofrecen una matriz con la cual es posible releer la vida urbana, operar nuevas formas de diseñar y concebir el espacio de vida e intercambio en la ciudad, respondiendo así a lo efímero de lo emocional, histórico, físico y social.

Palabras clave:Arquitectura efímera, arquitectura contemporánea, pabellones, ciudades, Río de Janeiro

\begin{abstract}
In these first decades of the 21 st century we live a specific moment of high modernity, characterized by transience in various spheres of social and economic relations, an ephemeral condition that expresses itself in the city and builds new spatial and architectural dynamics. This article seeks to reflect on the relationship between this ephemeral space-time condition and the contemporary society, observing how it materializes in the city. Specifically, we seek to understand how these characteristics are assimilated in architecture in the case of pavilions, one of the most ephemeral typologies in the field of architecture. To this end, we start from the discussion of some authors who deal with the paradigm shift from modernity to postmodernity, to then systematize and discuss the concepts of dynamism, reversibility, flexibility and unpredictability, with which the cases of the temporary pavilions will be evaluated. Finally, we conclude that these concepts offer a matrix with which it is possible to reread urban life, to operate on new ways of designing and conceiving the space of living and exchange in the city, thus responding to the ephemerality of the emotional, historical, physical and social.
\end{abstract}

Keywords: Ephemeral architecture, contemporary architecture, pavilions, cities, Rio de Janeiro 


\section{INTRODUÇÃO}

\section{A CONDIÇÃO EFÊMERA}


mundo influencia diretamente na personalidade, na motivação e no comportamento do indivíduo, que passa a exercer uma relação desapegada, superficial e transitória com o espaço, os objetos e demais indivíduos.

Trata-se de um contexto marcado pelos ganhos de velocidade resultantes do enfrentamento das necessidades urbanas em transformação, que, segundo Ascher (1998), modificaram consideravelmente as escalas da vida cotidiana, produzindo novas formas urbanas. A velocidade dos deslocamentos transformou a forma como os objetos e espaços são apreciados, assim como impactou no uso e apropriação dos espaços, modificando consideravelmente a organização temporal da sociedade (Ascher, 1998). Esse estágio contemporâneo de aceleração da modernização é denominado por ele como a Terceira Modernidade, caracterizada por traços como: mudança de escala e forma das cidades; transformação dos sistemas urbanos de mobilidade; formação de espaços-tempos individuais; formação de vínculos mais numerosos e menos estáveis e; novas relações de risco advindas de um ambiente geral de incertezas.

Essa mesma fase de aceleração do mundo contemporâneo é denominada por Augé (1992) como Supermodernidade, momento de mudanças aceleradas que impactaram profundamente nas categorias do tempo, do espaço e do indivíduo. $\bigcirc$ tempo teria sido afetado pela superabundância factual, em que a aceleração da história corresponde à multiplicação de acontecimentos; a mudança do espaço estaria ligada ao encolhimento do planeta devido ao deslocamento dos parâmetros espaciais e à mudança de escala da era atual; e o indivíduo teria sido impactado pela individualização das referências presente nessa nova condição espaço-temporal de incertezas.

Sennett (1994) complementa que o indivíduo (pós) moderno é acima de tudo um ser humano móvel, e que:

[...] como o desejo de livre locomoção triunfou sobre os clamores sensoriais do espaço através do qual o corpo se move, o indivíduo moderno sofre uma espécie de crise tátil: deslocar-se ajuda a insensibilizar o corpo (Sennett, 1997, p. 214).

autor parte de reflexões sobre as relações sociais no espaço público pós-moderno, caracterizado pela proliferação de "corpos passivos" insensíveis ao mundo real, condição em grande parte causada pela experiência da velocidade. Nesse contexto de individualismo, o espaço público se converte em um lugar mais para se passar a vista do que destinado a conversações (1997).

Influenciado pelos escritos de Sennett, Bauman (200I) conceitua a condição contemporânea como a Modernidade Líquida, estágio mais dinâmico ligado à nova relação entre espaço e tempo, na qual a aceleração da velocidade do movimento se reduziu à instantaneidade. Enquanto a antiga modernidade, pesada e sólida, representou a era 
da conquista territorial, a modernidade líquida representa a desterritorialização, o retorno ou aproximação do ser humano sedentário de outrora ao nomadismo (Sansão Fontes, 2013).

\footnotetext{
A mudança em questão é a nova irrelevância do espaço, disfarçada de aniquilação do tempo. No universo de software e da viagem à velocidade da luz, o espaço pode ser atravessado, literalmente, em "tempo nenhum"; cancela-se a diferença entre "longe" e "aqui". $\bigcirc$ espaço não impõe mais limites à ação e seus efeitos, e conta pouco, ou nem conta (Bauman, 200।, p. 136).
}

O autor introduz a figura do sujeito nômade, não mais visto em uma posição marginal como outrora, mas em uma expressão de autonomia, liberdade e poder, colocando em evidência o valor da curta duração como preponderante na contemporaneidade. Segundo ele, testemunhamos a vingança do nomadismo contra o princípio da territorialidade e do assentamento, e, sob este ponto de vista, a cidade deverá passar a suportar o trânsito deste "novo" elemento móvel (Sansão Fontes, 2013).

Essa visão sintoniza com a interpretação de Lipovetsky (1989), que sustenta que, dada a ambiguidade da condição efêmera, é necessário reduzir a inclinação obscurantista do efêmero como um estado de alienação e aumentar sua inclinação esclarecida, que são suas potencialidades de libertação. Nesse cenário, defende o efêmero como um sinal de liberdade e uma válvula de escape para o indivíduo.

Estamos tratando, portanto, de uma condição contemporânea seja ela alta modernidade, pós-modernidade, modernidade líquida, terceira modernidade, supermodernidade - revestida de características específicas e identificáveis. Segundo a discussão dos autores, essas feições remetem a temas como a aceleração do tempo e a instantaneidade; a práticas efêmeras e nômades na cidade; a indeterminação e as incertezas sobre o futuro; e a fluidez e descontinuidade do espaço-tempo atual, trazendo à tona conceitos como dinamismo, reversibilidade, flexibilidade e imprevisibilidade (Sansão Fontes, 2013), conforme discutiremos mais adiante.

\section{AS INTERVENÇÕES TEMPORÁRIAS}

Nesse contexto, o temporário, aquilo de pouca duração ou impermanente, surge como uma resposta à descontinuidade espaço-temporal. Quando estas temporalidades são capazes de se manifestar física e socialmente no espaço e modificar as condutas, entramos no campo das "intervenções temporárias". As intervenções temporárias são pequenas ações efêmeras realizadas no espaço urbano que rompem com a organização contínua e homogênea do cotidiano (Sansão Fontes e Couri Fabião, 2016). Partimos da premissa de que o que difere as intervenções tem- 
porárias de outras ações de urbanismo D/Y interinas, cuja ambição pode ser a permanência pelo maior tempo possível (Vallance et al, 20 17), é justamente a sua intenção de impermanência, o que as aproxima do contexto contemporâneo discutido anteriormente. Segundo a classificação de Sansão-Fontes (20।3), intervenções temporárias podem assumir diferentes tipologias, sejam elas apropriações espontâneas do espaço público, intervenções de arte pública, instalações arquitetônicas, festas locais ou ainda ações táticas (LablT, 20 I5). Para esse artigo, discutiremos um tipo particular de instalação arquitetônica: os pavilhões temporários.

O pavilhão temporário é uma derivação do arquétipo do pavilhão em arquitetura. Um pavilhão, segundo acepções de dicionário, ${ }^{2}$ pode corresponder historicamente a: (I) uma ala integrante de um edifício, destinada a um uso específico, como por exemplo ocorria em hospitais, palácios e escolas de tipologias "pavilhonares"; (2) uma pequena edificação isolada, usada principalmente para servir de abrigo, como implantado, por exemplo, em jardins e parques do século XVIII; (3) uma construção leve e de fácil remoção, geralmente não compartimentada, usada principalmente em feiras e exposições no século XX; ou ainda a (4) uma construção, às vezes isolada e outras vezes associada a um edifício, em geral com uso secundário em relação ao edifício principal (Puente, 2000), como ocorre, por exemplo, em residências, galerias ou museus contemporâneos.

Com relação à sua temporalidade, Asato (20|8) menciona que houve na história da arquitetura pavilhões projetados para serem permanentes, assim como outros projetados para serem temporários, mas que se tornaram permanentes. Há também aqueles emblemáticos pavilhões temporários, reconhecidos nas exposições internacionais e à serviço das grandes narrativas da modernidade. A contemporaneidade, no entanto, vem sendo um terreno fértil para a criação de pavilhões pensados para serem fisicamente temporários, mas também capazes de abrigar uma experiência temporária.

Segundo Lipovetski (2016), a arquitetura exprime o culto contemporâneo à leveza. Ela invadiu nossa rotina e transformou nosso imaginário, tornando-se um valor e um ideal. Calvino (1990) já havia proposto a leveza como um dos valores literários para o século $X X \mid$. Considerando este aspecto como algo presente no tema dos pavilhões, este artigo tratará dos pavilhões contemporâneos de natureza leve e transitória, que operam como abrigo para distintas atividades igualmente impermanentes.

1 Do it youself - faça você mesmo, em tradução livre.

2 Segundo Michaelis: Dicionário Brasileiro da Língua Portuguesa. 


\section{METODOLOGÍA}

\section{DISCUSSÃO E RESULTADOS}




\section{ESCALA DA CIDADE: PAVILHÃO HUMANIDADE (2012)}

o território num contínuo fazer e desfazer (Sansão Fontes, 2013). Uma das estratégias contemporâneas de projeto apontadas por Enia e Martella (2019) é o que denominam como "fazer quase nada". ${ }^{3}$ Segundo eles, uma maneira possível de fazer quase nada é projetar uma intervenção temporária destinada a ocupar um local apenas por um período limitado, restaurando sua configuração original em um período relativamente curto (Enia e Martella, 2019).

Os conceitos de flexibilidade e imprevisibilidade, por sua vez, relacionam-se ao fim da rigidez, que proclama o destino aberto da cidade, entendida como um território imprevisível onde não cabem mais as regras rígidas da velha modernidade (Sansão Fontes, 2013). Flexibilizar, segundo Gausa et al. (200 I), significa abrir ao indeterminado. Em uma sociedade em permanente mudança, resultado de transformações tecnológicas, econômicas, culturais e sociais, a flexibilidade é cada vez mais um desafio para a arquitetura. Segundo Silva e Eloy (20।2), a mobilidade e as constantes alterações da vida humana geram novas necessidades e atividades dos indivíduos, demandando a adaptabilidade, flexibilidade e abertura dos espaços construídos ao imprevisto.

No entanto, cabe ressaltar a diferença entre os conceitos de reversibilidade e flexibilidade, que para Sansão Fontes (2013) está na transformação final do espaço. A reversibilidade é encarada como uma qualidade elástica que pressupõe a dinâmica intermitente do espaço, enquanto a flexibilidade está relacionada a um campo aberto à transformação.

A seguir, articularemos esses conceitos às três obras de pavilhões temporários, buscando demonstrar como a condição efêmera se concretiza na cidade, por meio da arquitetura.

O Pavilhão Humanidade é uma megaestrutura de andaimes, com dimensões de 170 metros de comprimento, 30 de largura e 20 de altura, instalado no Forte de Copacabana para prover infraestrutura para a Conferência da ONU Rio + 20. É um projeto de Carla Juaçaba e Bia Lessa que contém salas expositivas, uma biblioteca e um auditório para 500 pessoas.

Segundo Ribeiro (2019), foram premissas do projeto a concepção criativa relacionada ao prazer estético e a redução do impacto ambiental a partir do sistema construtivo adotado. A estrutura, uma malha metálica transparente, aberta e totalmente desmontável, compõe um edifício virtual (Segre, 2012) em cujo "interior" são instalados os containers expositivos. $\bigcirc$ conjunto é acessado por um sistema de rampas que estabelece um percurso contínuo desde o térreo até o terraço panorâmico, criando no público "uma experiência inédita, cheia de surpresas e de impactos visuais, espaciais, mediáticos, em uma sequência de sons, cores, dados, informações e percepções sensoriais" (Segre, 2012$)$. 


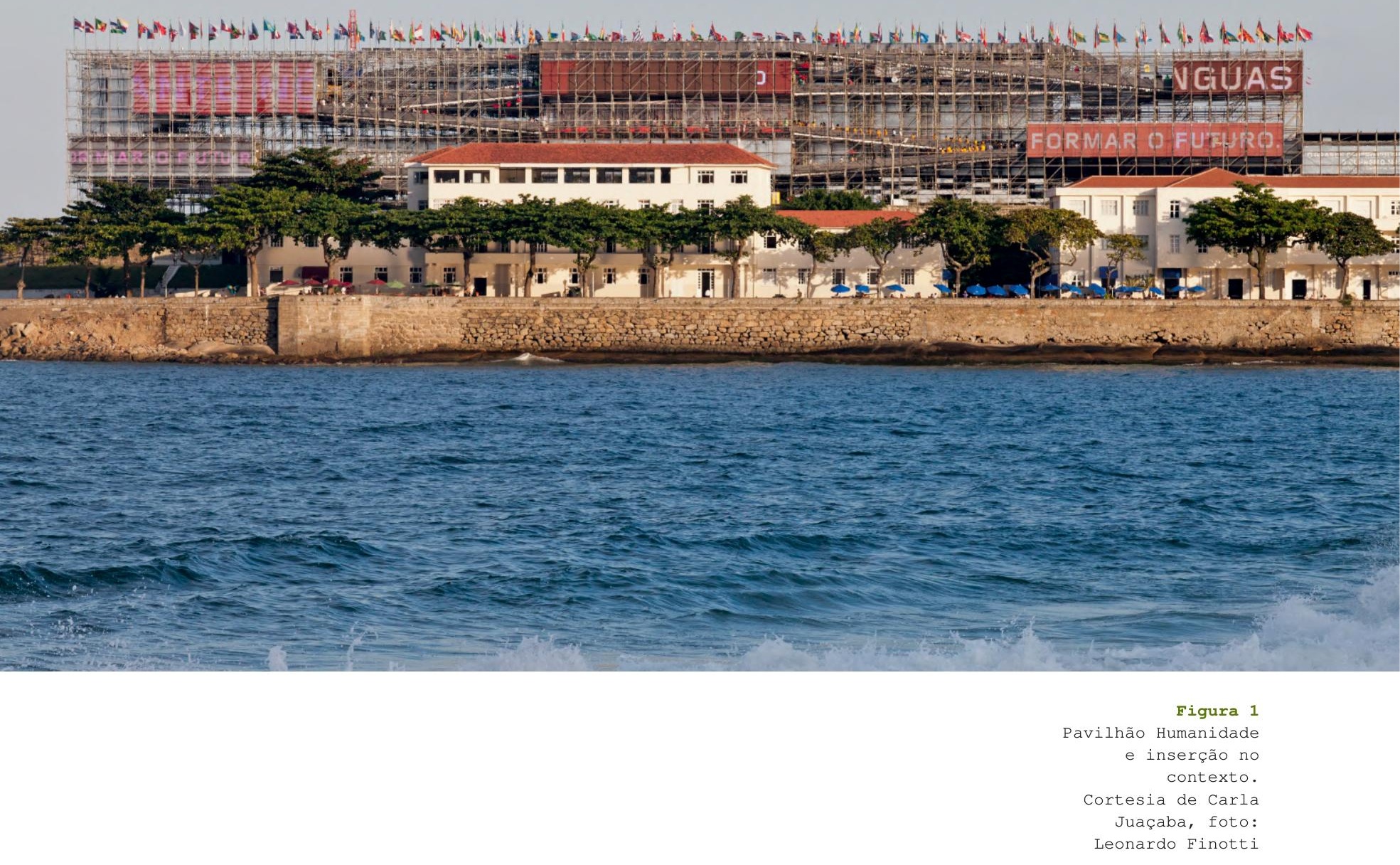

conceito de dinamismo está presente em vários aspectos do pavilhão, desde a forma como é implantado até a maneira como é apropriado. Segundo Bia Lessa, uma das autoras do pavilhão, o desejo era que a vista e o clima fossem materiais expositivos, tanto quanto os textos, as esculturas, os desenhos, as máquinas (Lessa apud Ribeiro, 2019). Assim, o pavilhão surge, utilizando-se das forças da natureza, na forma de uma megaestrutura vazada, como uma grande janela para a paisagem permitindo a passagem do vento, elevada do solo permitindo sua liberação para um jardim e coroada por um terraço de onde era possível apreciar a magnífica vista do Forte de Copacabana. A fruição dos visitantes se dá através de rampas que cortam todo o conjunto e fazem com que o usuário se desloque pelo pavilhão. Segundo Ribeiro (2019, p. I33) "foi proposta uma tensão dinâmica entre interior e exterior, onde mesmo dentro se estava fora. " Dessa forma, evita-se a circulação pontual, fazendo com que o usuário, deslocando-se através da estrutura vazada, faça parte da dinamicidade da obra.

processo construtivo do pavilhão constitui-se, em sua essência, dentro do conceito da reversibilidade, uma vez que a estrutura de andaimes 
ARQUITECTURA EFÍMERA

pressupõe a reutilização, por meio do processo de montagem e desmontagem, sendo um sistema que existe antes, durante e continuará existindo após a presença temporária do pavilhão (Ribeiro, 2019), em um eterno fazer e desfazer (Sansão Fontes, 20 l 3).

O Pavilhão Humanidade é a única entre as três obras discutidas aqui que contém um programa definido. Entretanto, isso não retira seu caráter flexível, uma vez que, nesse caso, a flexibilidade se dá no sistema modular adotado. Também, a partir do ponto de vista da modulação construtiva, o fato de ser uma instalação que reinterpreta os andaimes como estrutura para o pavilhão, gera um jogo de narrativas no visitante, que associa esse tipo de sistema ao temporário, provisório, móvel e flexível. Trata-se, assim, de uma dimensão também estética, estabelecendo uma relação entre usuário e lugar, potencializando a dimensão efêmera na percepção do visitante. Esse deslocamento na percepção do pavilhão como algo efêmero não só temporalmente, mas também espacialmente, gera também uma imprevisibilidade no ato de entrar e percorrer, pois o que normalmente é reconhecido como uma estrutura impermanente e de caráter secundário, uma não-arquitetura, no pavilhão torna-se o edifício.

Figura 2

Pavilhão Humanidade

e a relação com a

paisagem.

Elaboração Adriana

Sansão
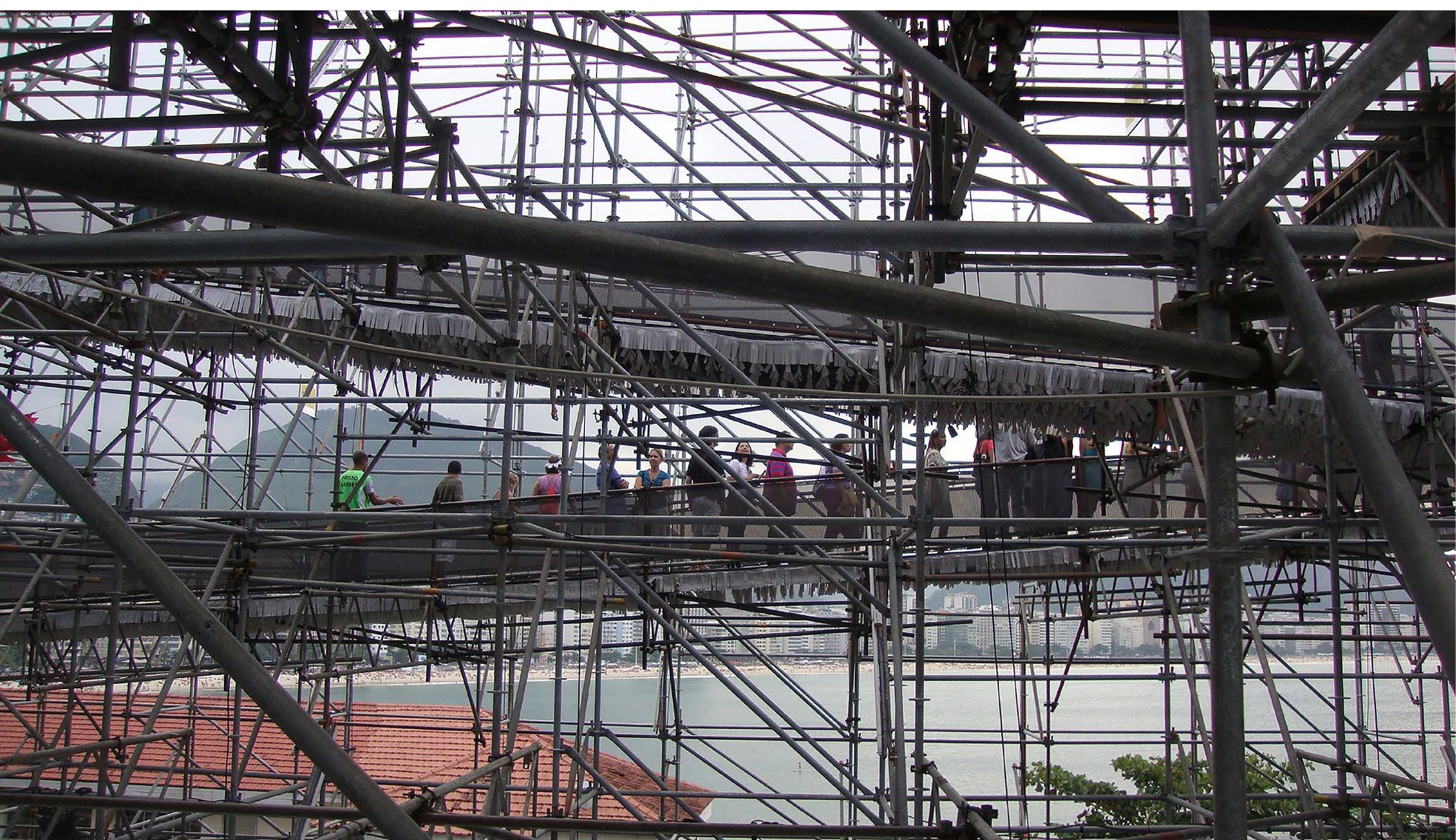


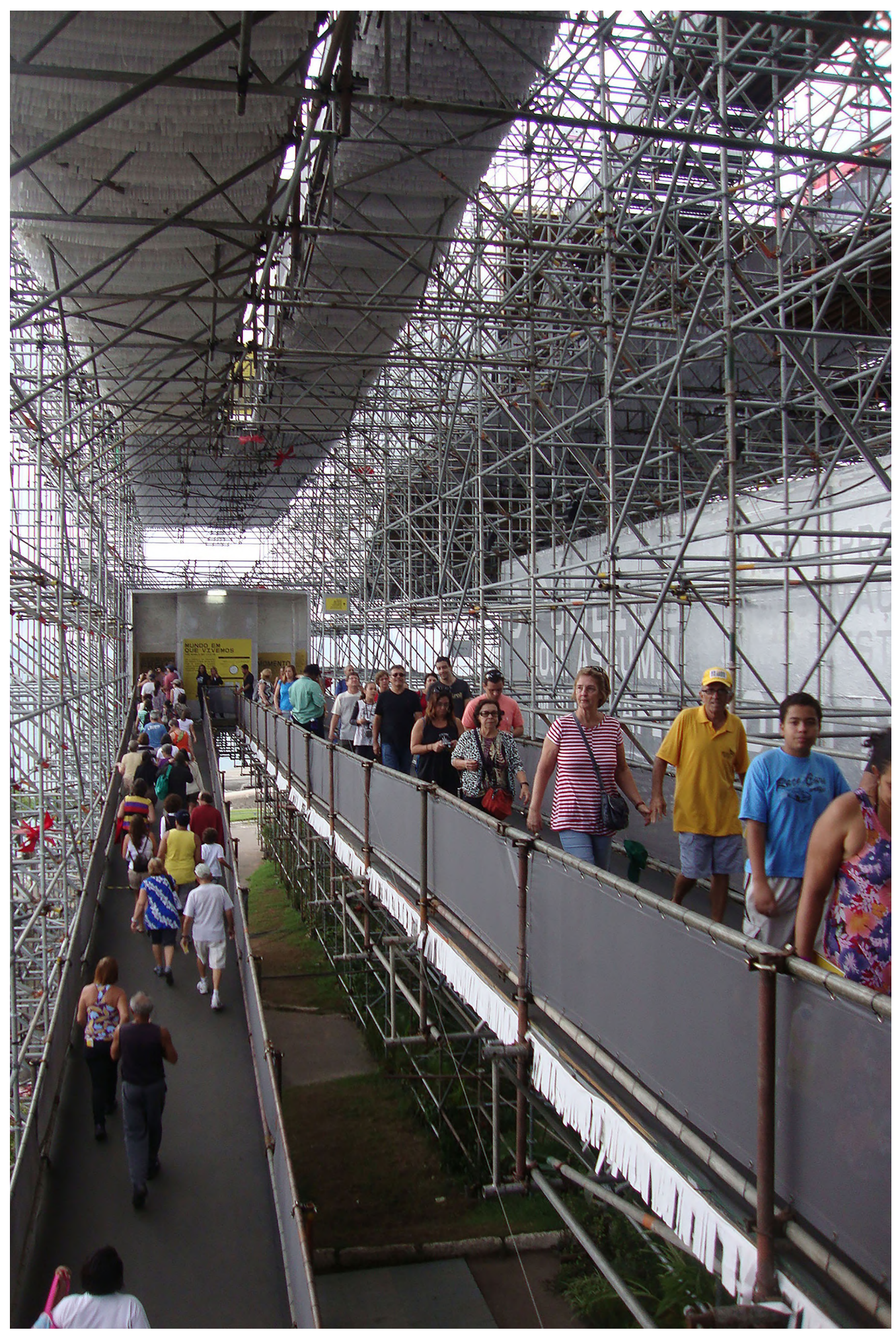




\section{ESCALA DA PRAÇA: PAVILHÃO TORNADO (2017)}

4 Professores responsáveis: Adriana Sansão Fontes, Andrés Passaro e Gonçalo Castro Henriques.

5 Conceito que surge da fusão das palavras "simplicity" e "complexity", ou simplicidade e complexidade.
O Pavilhão Tornado é uma pequena estrutura instalada na praça central do Parque Tecnológico da Universidade Federal do Rio de Janeiro (UFRJ), localizado na Cidade Universitária, à margem da Baía de Guanabara, no Rio de Janeiro. O local é um sítio modernista pouco atrativo para o uso cotidiano, pela carência de estruturas de média escala capazes de oferecer uma vida exterior ao público que utiliza os edifícios lá instalados. Assim, o ambiente do Parque Tecnológico é pouco frequentado e são raros os casos de uso e apropriação de seus amplos espaços públicos (Passaro et al, 2019).

O Pavilhão surge, portanto, dessa urgência em ativar dita "praça" subutilizada. A motivação para tal foi uma parceria entre o PROURB-FAU/UFRJ, através de dois de seus laboratórios, LabIT e $\mathrm{LAMO}^{\mathrm{A}}{ }^{4}$, com a Faculdade de Arquitetura da Universidade de Lisboa e o Parque Tecnológico da UFRJ. Foi criada uma disciplina reunindo estudantes de diferentes áreas do conhecimento, onde foram formados grupos multidisciplinares para pensar propostas de pequenas estruturas que pudessem ativar a praça, utilizando como premissas as superfícies regradas e como processo a geração e a fabricação digital.

A proposta escolhida para construção foi projetada a partir de sarrafos de $4 \mathrm{~cm} \times 8 \mathrm{~cm}$ com $3 \mathrm{~m}$ de comprimento com ligações em parafusos. $\bigcirc$ pensamento que originou a geometria partiu das rotações incrementais de dois quadrados em sentidos opostos, o que resultou em uma geometria com aparência retorcida, que, apesar de retilínea, forma também uma imagem orgânica, especialmente em seu interior (LablT, 20l7), contribuindo para a dinamicidade da forma, a que gera a impressão de um movimento em giro sobre seu eixo longitudinal. $\bigcirc$ processo de criação do pavilhão se encaixa dentro do preceito definido por Kolarevic (2016) como Simplexity, ${ }^{5}$ uma forma complexa que surge da utilização de regras de modelagem e de fabricação simplificadas, uma vez que o projeto parte de uma linha de $3 \mathrm{~m}$ de comprimento, com a qual foram feitas operações simples de movimentação e rotação em série, definindo a forma final (Passaro et al, 2019).

O pavilhão "pousa" na praça sem realizar quase nenhuma interferência. Sua implantação estabelece um eixo diagonal em relação ao vértice da praça, buscando um melhor ângulo de visualização e um acesso convidativo, uma vez que se abre para o conjunto de edifícios mais vivazes do entorno. Essa tática de "pousar" sem deixar maiores rastros dialoga com a operação do "fazer quase nada" já mencionada. $\bigcirc$ pavilhão, pensado para uma curta duração (teve a presença de 18 meses), explora o aspecto reversível do espaço tanto em seu processo construtivo, baseado na montagem, quanto na implantação em si, realizada sem a necessidade de fundações, enfatizando sua essência efêmera. $\bigcirc$ reversível, desta forma, está associado a essa leveza do material, da estrutura e do processo 


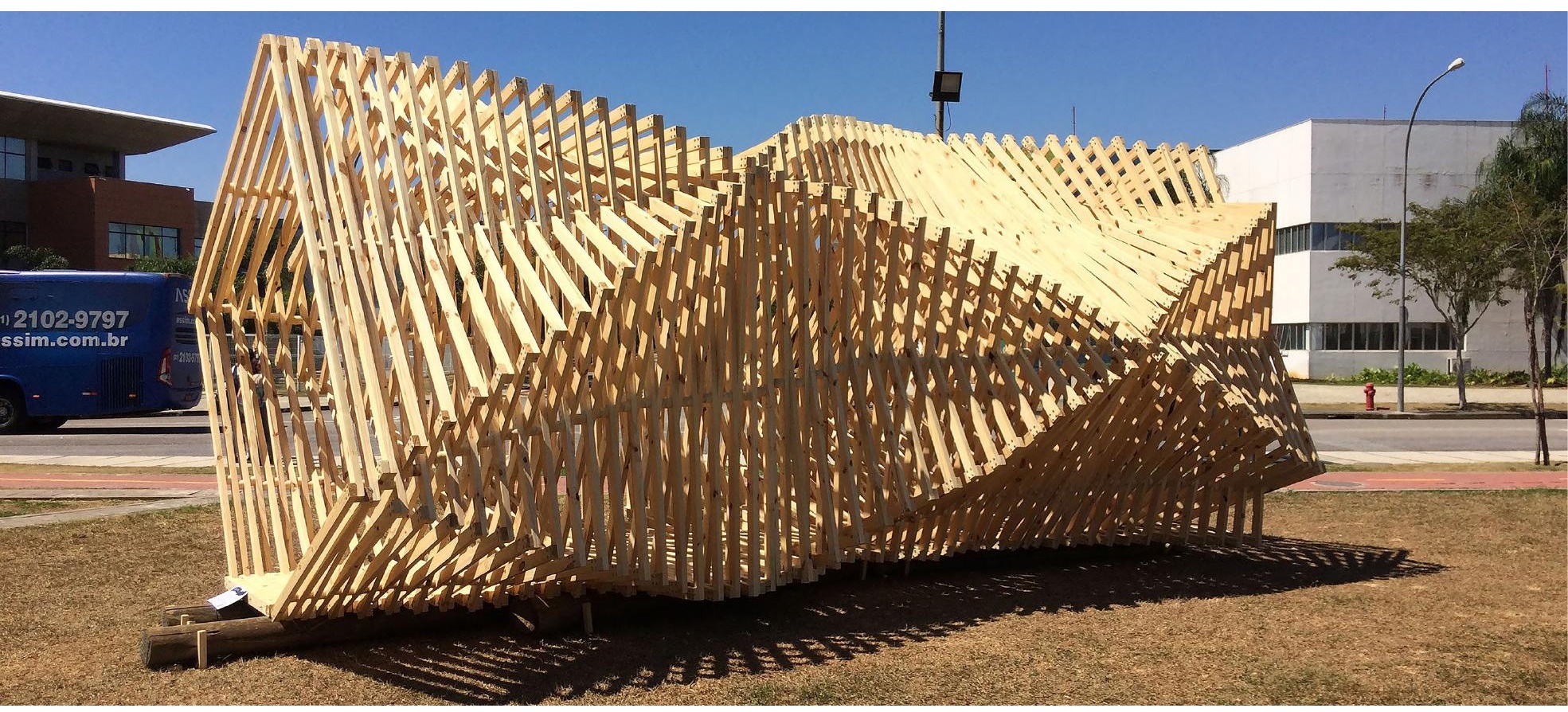

\section{ESCALA DO EDIFÍCIO: EX.VAZIO (2018)}

Ex.Vazio é um pavilhão inflável instalado no mezanino da Faculdade de Arquitetura e Urbanismo da UFRJ. Esse espaço abrigou a Biblioteca Lúcio Costa, transferida do local por conta da degradação paulatina que o espaço vem sofrendo desde 2016, processo que vem negligenciando sua potência arquitetônica (Sansão-Fontes, Espósito e Arbusà, 2019) dentro do edifício modernista que abriga a Faculdade.

p pavilhão surge, portanto, na tentativa de ressignificar e reocupar esse lugar tão emblemático para a comunidade acadêmica. A motivação para tal foi uma oficina realizada através de uma parceria entre o LablT-PROURB e o Penique Productions, para a qual foram selecionados 50 estudantes da Faculdade de Arquitetura e Urbanismo, reunidos para fabricar, montar e encher o grande inflável.

A obra ocupou o espaço do mezanino, que tem uma planta trapezoidal com dimensões aproximadas de $10 \mathrm{~m} \times 20 \mathrm{~m}$ (bases) $\times 28$ m (altura) e pé direito de 4,5 m. Foi construída utilizando somente plástico reciclado, fita adesiva e ar, proveniente da instalação de um único ventilador que mantém a obra inflada. Sua principal característica é a total aderência aos limites físicos do espaço, adquirindo a forma da arquitetura envolvente e alterando a percepção espacial de suas dimensões, luz e forma. Uma obra feita de ar, que incorpora em sua essência o conceito de dinamismo de fluxos materiais e imateriais na organização dos espaços. 
O pavilhão ocupou o espaço disponível sem a necessidade de nenhuma alteração, e preencheu o que antes era um vazio físico e social. A "bolha" ocupou o espaço e se debruçou sobre o pavimento térreo do edifício estabelecendo um novo marco temporal. Após uma intensa apropriação de quatro dias, em que o inflável foi palco das mais diversas atividades, como aulas de desenho, performances de dança e música, descanso e interação social, recebendo mais de 1300 visitantes, o pavilhão foi esvaziado e o local restituído de sua aparência anterior, colaborando para a reversibilidade da intervenção. Nesse sentido, é importante salientar a extrema leveza física da intervenção, conformada pelo plástico como material e a pressão de ar como "estrutura" do inflável, que, para ganhar sua forma definitiva, precisa de um abrangente, neste caso o edifício preexistente, interagindo com o inflável. Entre edifício e pressão de ar, é a monocromia e materialidade do plástico o que ganha protagonismo como modificador do local.

No tocante à apropriação do espaço, como já mencionado, o pavilhão foi um evento de alta circulação e permanência, mostrando-se um espaço espontaneamente aberto ao imprevisto e flexível para adaptar-se até mesmo a situações em que sua materialidade (um plástico pouco espesso) poderia parecer inadequada, como as performances de dança. Sua flexibilidade, portanto, foi capaz de testar diversas novas apropriações não previstas, auxiliando a imaginar destinos futuros para o espaço. Expressões como essa podem se cristalizar em formas mais permanentes de memória e narrativa coletiva (Tardiveau e Mallo, 20|4), e, nesse sentido, vale comentar que essa intervenção deixou marcas permanentes (Sansão Fontes, 20l3), uma vez que, após o inflável, esse espaço, antes desocupado e esquecido, se converteu em um local oficial de exposições temporárias, que estão sempre atuando elasticamente sobre o sítio.

○ pavilhão inflável teve a duração de somente quatro dias, tendo sido a intervenção mais efêmera das três ações aqui apresentadas.

Os três pavilhões temporários, por suas características arquitetônicas e pelas formas de ocupação e uso, respondem à condição de efemeridade discutida no artigo. Nos três casos, o efêmero, a partir do ponto de vista espacial, responde a uma temporalidade diferente. No primeiro caso, o Pavilhão Humanidade, trata-se de uma intervenção monumental e modular de duração de 10 dias. $\bigcirc$ pavilhão Tornado corresponde a uma intervenção de superfície regrada, de pequena escala e de duração de 18 meses. Já no caso do pavilhão Ex.Vazio, trata-se de uma intervenção de quatro dias, que se apoia na arquitetura existente, sem forma nem espacialidade próprias, porém, fundamental para a reinterpretação do local interferido. 

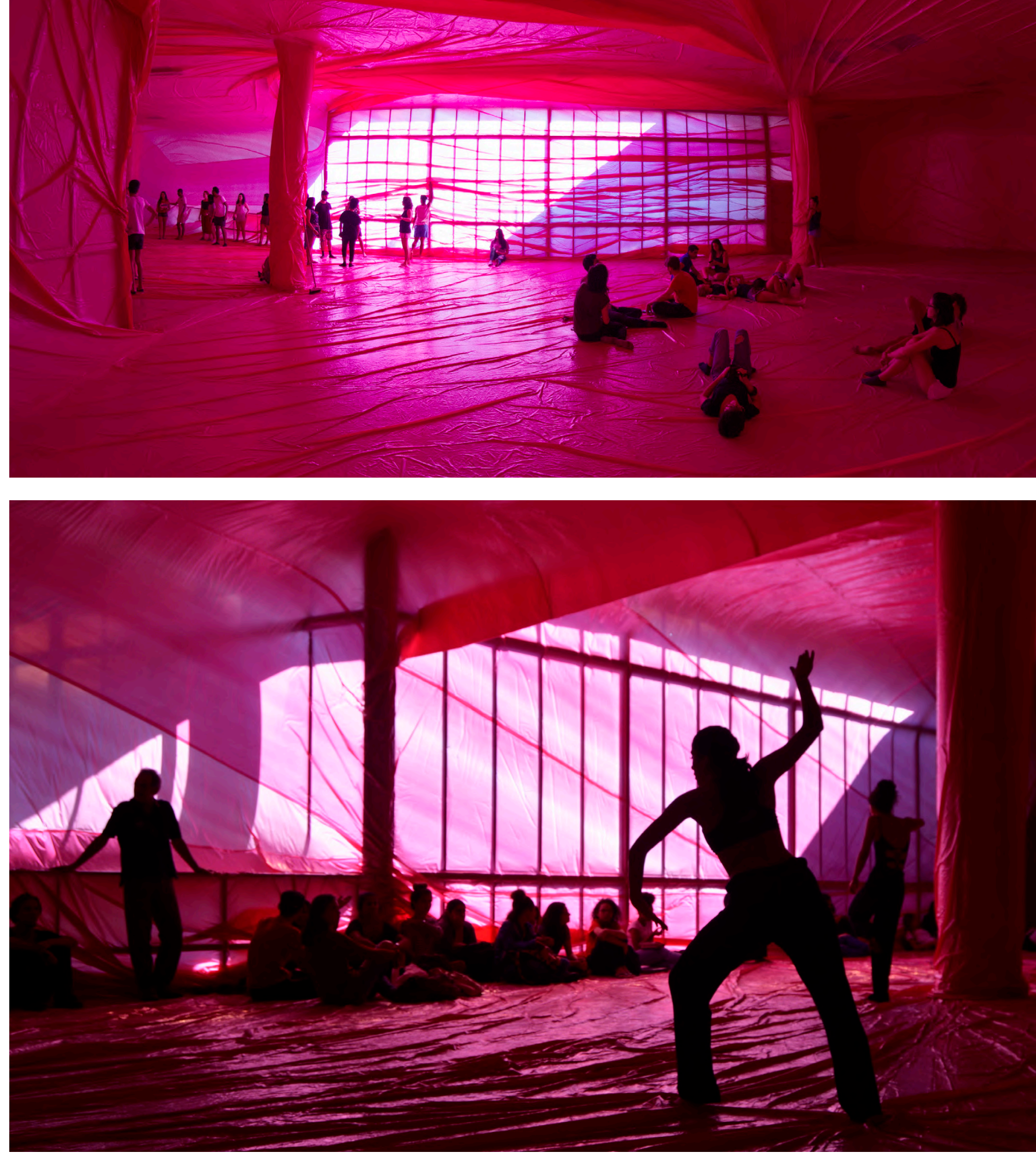


\section{CONCLUSÃO}

Como colocado na convocatória deste número da revista Arquitecturas del Sur, "efímera es la condición que relata, entre otras, la corta pervivencia de un hecho, emotivo, histórico, físico o social". Nossas cidades estão atravessando processos de profundas alterações, tanto físicas como sociais, nas quais o espaço urbano é cada vez menos valorizado como lugar de permanência e sociabilidade. Numa época em que as tecnologias da comunicação e a intensificação da velocidade, tanto física como informacional, têm modificado profundamente nossa capacidade de compreender o espaço urbano, a arquitetura deve também desenvolver novas estratégias para responder a esses novos desafios que envolvem a presença do cidadão no espaço urbano e suas formas de perceber seu entorno.

Neste ponto, a arquitetura efêmera pode operar aproveitando as oportunidades deixadas por essa fronteira entre o permanente da cidade e a aceleração da vida urbana. No caso dos pavilhões apresentados, embora consistam em interferências específicas em relação ao contexto em que se localizam e às técnicas, formas e materiais que as caracterizam, também revelam certa universalidade nas estratégias de intervenção na cidade contemporânea. As características de dinamismo, reversibilidade, flexibilidade e imprevisibilidade oferecem uma matriz com a qual é possível reler essa vida urbana, para operar sobre novas formas de projetar e conceber o espaço de convívio e troca na cidade, respondendo, assim, a essa efemeridade do "emotivo, histórico, físico e social". Pois, como colocado por Ferguson (2014), o temporário implica também um ato de mudança ou reinterpretação do permanente, como forma de revelar seu potencial de apropriação. 


\section{REFERÊNCIAS BIBLIOGRÁFICAS}

ASATO, A. Pavilions as Urban Placemakers: Temporary Architecture and Community Engagement. Portland: University Honors Theses. 2018.

ASCHER, F. Mobilité e temps de la vie quotidienne. In: Les débats sur la ville 1. Bordeaux: Éditions Confluences. 1998.

AUGÉ, M. Não-Lugares. Introdução a uma antropologia da supermodernidade. Campinas: Papirus. 1994.

BAUMAN, Z. Modernidade líquida. Rio de Janeiro: Jorge Zahar. [(2000)2001].

CALVINO, I. Seis propostas para o próximo milênio. São Paulo: Companhia das Letras. 1990.

ENIA, M. e MARTELLA, F. Reducing architecture: Doing almost nothing as a city-making strategy in 21st century architecture. Frontiers of Architectural Research, 2019, 8, PP. 154-163.

FERGUSON, F. Make_Shift City. Renegotiating the Urban Commons. Berlim: Jovis Verlag. 2014.

GAUSA, M. et al. Diccionario metápolis de arquitectura avanzada. Ciudad y tecnología en la sociedad de la información. Barcelona: Actar. 2001.

HARVEY, D. A condição pós-moderna. São Paulo: Loyola. [(1990)1993].

KOLAREVIC, B. Simplexity (and Complicity) in Architecture. In: Proceedings of the 34th eCAADe Conference, Oulu, Finland: Herneoja, Aulikki; Toni Österlund and Piia Markkanen (eds). University of Oulu, 2016, 1, pp. 25-31.

LABIT - Laboratório de Intervenções Temporárias e Urbanismo Tático. Disponível em: http://intervencoestemporarias.com.br/. Acesso em 16/11/2019.

LEHTOVUORI, P. e RUOPPILA, S. Temporary uses as means of experimental urban planning. SAJ - Serbian Architectural Journal, 2012, 4, pp. $29-53$.

LIPOVETSKY, G. O império do efêmero. A moda e seu destino nas sociedades modernas. São Paulo: Cia das Letras. 1989.

LIPOVETSKY, G. Da leveza: Para uma civilização do ligeiro. Lisboa, Portugal: Edições 70. 2016.

PASSARO, A. et al. Tornado Pavilion. Simplexity, almost nothing, but human expanded abilities. In: eCAADe 37 / SIGraDi 23 - Design - Collaboration and participation, 2019. 1, pp. 305-314.

PUENTE, M. Pabellones de exposición - 100 años. Barcelona: Editorial Gustavo Gili. 2000.

RIBEIRO, S. Do descartável ao efêmero: a redução do impacto ambiental no Design dos Espaços do Acontecimento. Dissertação de Mestrado em Design. Rio de Janeiro: Pontifícia Universidade Católica do Rio de Janeiro. 2019.

SANSÃO FONTES, A. Intervenções temporárias, marcas permanentes. Apropriações, arte e festa na cidade contemporânea. Rio de Janeiro: Casa da Palavra. 2013.

SANSÃO FONTES, A.; ESPÓSITO, F. e ARBUSÀ, S. Ar-quiteturas. Os infláveis como estratégia de reinterpretação do lugar. Revista Prumo, 2019, 7, pp. 138-151.

SANSÃO FONTES, A. e COURI FABIÃO, A. Além do público - privado: intervenções temporárias e criação de espaços coletivos no Rio de Janeiro. Revista de Arquitectura, 2016, 18(2), pp. 27-39.

SEGRE, R. Pavilhão Humanidade 2012. Uma arquitetura frágil e sustentável no evento Rio+20. Vitruvius Projetos, 2012, São Paulo, ano 12, n. pp. 138-139.02.

SENNETT, R. Carne e Pedra. Rio de Janeiro: Record. 1994.

SILVA, J. e ELOY, S. Arquitetura flexível: movimento e sistemas cinéticos. Arq. urb, 2012. 8, pp. 190-199.

TARDIVEAU, A. e MALLO, D. Unpacking and Challenging Habitus: An Approach to Temporary Urbanism as a Socially Engaged Practice. Journal of Urban Design, 2014. 19(4), pp. 456-472.

VALLANCE, S. et al. Temporary use and the onto-politics of 'public' space. Cities, 2017. 70, pp. 83-90. 